\title{
O JOGO DA CAPTURA DA PRINCESA E A INTRODUÇÃO DA NOÇÃO DE ÁRVORE DE POSSIBILIDADES
}

\section{THE PRINCESS'S CAPTURE GAME AND THE INTRODUCTION OF THE TREE NOTION OF POSSIBILITIES}

\author{
Rafael Rix Geronimo ${ }^{1}$ \\ Daniel Couto Gatti ${ }^{2}$
}

\begin{abstract}
Resumo: Esse artigo teve como objetivo descrever um relato acerca da elaboração e proposição de um jogo de tabuleiro, para introduzir a noção de árvore de possibilidades, para alunos do nono ano do Ensino Fundamental. A metodologia utilizada foi a pesquisa-ação, na qual os pesquisadores intervieram sobre o objeto pesquisado. O jogo foi proposto em três sessões de quarenta e cinco minutos cada uma. Na primeira, os pesquisadores apresentaram o jogo e explicaram as regras, na segunda houve uma intervenção, com vistas a mostrar uma estratégia de jogo mais efetiva (o conhecimento sobre árvore de possibilidades) e na terceira foi pedido que jogassem novamente. Como resultados, foi possível observar que a intervenção dos pesquisadores foi capaz de fazer com que os estudantes mudassem suas estratégias de jogo, o que pode significar que eles atribuíram significado a noção de árvore de possibilidades, de maneira lúdica.
\end{abstract}

Palavras-chave: Jogo de Tabuleiro; Combinatória; Ensino Fundamental.

Abstract: This article aimed to describe a story about the elaboration and proposal of a board game, to introduce the notion of tree of possibilities, for students of the ninth grade of elementary school. The methodology used was action research, in which the researchers intervened on the researched object. The game was proposed in three sessions of forty-five minutes each. In the first, the researchers presented the game and explained the rules, in the second there was an intervention, with a view to showing a more effective game strategy (knowledge about the tree of possibilities) and in the third, they were asked to play again. As a result, it was possible to observe that the researchers' intervention was able to make students change their game strategies, which may mean that they attributed meaning to the notion of possibilities tree, in a playful way.

Keywords: Board Game; Combinatorial; Elementary School.

\section{Introdução}

Consideramos que uma direção para toda a área de ensino pode ser a proposição de jogos para ensinar. Uma abordagem, para refletir acerca de jogos é a partir das ideias de Huizinga (2008), quando salientou acerca de sua função na sociedade, chegando à conclusão de que jogar é uma de suas bases. Assim, essa pode ser uma prática mais natural que realizar atividades e exercícios tradicionais.

\footnotetext{
${ }^{1}$ Doutorando em Educação Matemática pela Pontifícia Universidade Católica de São Paulo, PUC/SP. Professor na Prefeitura da Cidade de São Paulo, Brasil. E-mail: rgrix@ @otmail.com

${ }^{2}$ Doutor em Educação Matemática pela Pontifícia Universidade Católica de São Paulo, PUC/SP. Professor na Pontifícia Universidade Católica de São Paulo, Brasil. E-mail: daniel@ pucsp.br
} 


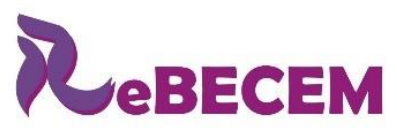

Revista Brasileira de Educação em

Ciências e Educação Matemática

DOI: http://dx.doi.org/10.33238/ReBECEM.2020.v.4.n.1.21884

Como exemplos dessa tendência podemos citar o trabalho de McGonigal (2012), quando expressou a ideia, presente em alguns jogos comerciais, de discutir problemas da sociedade. A autora comentou sobre a preocupação crescente de criadores de jogos em problematizar questões da sociedade atual. Dessa forma, o que se pretende neste artigo é discutir como especialistas da área da educação podem refletir ou se apropriar acerca desse tipo de estratégia.

Um exemplo pode ser o jogo "Chore Wars",, no qual os personagens ganham pontos à medida em que os jogadores realizam tarefas como lavar louça ou aspirar o pó, por exemplo. Existe uma competição para ver quem tem o melhor personagem, que é aquele que realizou maior quantidade de tarefas domésticas.

Outra iniciativa é o "Free Race" que é um jogo de quiz (perguntas e respostas) em que cada resposta certa tem como consequência uma doação de arroz - paga pelos patrocinadores do jogo - para o programa de alimentação da Organização das Nações Unidas.

Esse tipo de ideia também pode influenciar o ensino e é nesse contexto que situamos nossa iniciativa, de criar jogos que problematizem conhecimentos escolares, feitos por especialistas em educação, com o intuito de discutir caminhos de como lecionar na atualidade. Acreditamos que uma das possibilidades a serem propostas é justamente a criação e aplicação de jogos com objetivos educacionais.

Justificamos nossa investigação em Brasil (2017), quando indica que estratégias como jogos podem ser usadas para ajudar a dar significado a conhecimentos presentes no currículo do Ensino Fundamental. Esse documento salienta: “[...] orienta-se pelo pressuposto de que a aprendizagem em Matemática está intrinsecamente relacionada à compreensão, ou seja, à apreensão de significados dos objetos matemáticos, sem deixar de lado suas aplicações.” BRASIL (2017, p.232). Além da justificativa curricular, outra justificativa se baseia no interesse do pesquisador pela proposição de jogos com objetivos pedagógicos e pelo engajamento, mostrado pelos estudantes, com a aplicação desse tipo de estratégia.

É possível perceber que em Brasil (2017) foi proposto um ensino de matemática apoiado em aplicações que, no Ensino Fundamental, não precisam estar somente relacionadas ao cotidiano, pois podem fazer referência a outros contextos. Assim,

\footnotetext{
${ }^{3}$ Disponível em: <http://www.chorewars.com/>, acesso em 10/04/2018.

${ }^{4}$ Disponível em: <http://www.freerice.com/> acesso em 10/04/2018.
} 


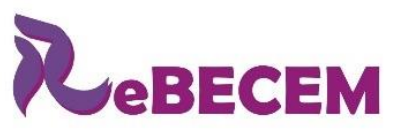

Revista Brasileira de Educação em

Ciências e Educação Matemática

DOI: http://dx.doi.org/10.33238/ReBECEM.2020.v.4.n.1.21884

consideramos que o ensino apoiado em estratégias como jogos pode ser útil. Escolhemos essa abordagem por levar em conta as ideias de Carstens e Beck (2005), de que vivemos a Geração Gamer, das pessoas que já nasceram imersas em diversas plataformas de jogos digitais e por isso, tem uma visão positiva desse tipo de atividade.

Essa visão favorável pode não se aplicar somente a plataformas informatizadas. Acreditamos que jogos analógicos, como os de tabuleiro ou de cartas, podem ter resultados positivos e devido a esse olhar, consideramos pertinente explorar essa alternativa.

Autores como Carstens e Beck (2005) acreditam que os jogos têm ganhado importância na sociedade e muitas discussões têm se dado acerca de alternativas a estratégias tradicionais de ensino. Nessa direção apontou Ribeiro (2009, p. 24), quando afirmou que: "[...] um trabalho com jogos matemáticos pode representar a mudança para uma configuração escolar, voltada ao desenvolvimento de sujeitos críticos, criativos, reflexivos, inventivos, entusiastas, num exercício permanente de promoção da autonomia".

Um exemplo foi a pesquisa de Geronimo (2011), que propôs um livro jogo para tratar da introdução a noção de incógnita, para o Ensino Fundamental. Outros exemplos, de utilização de jogos com objetivos pedagógicos, foram as pesquisas de Geronimo e Teixeira (2017) e de Geronimo (2018). Estes estudos propuseram jogos de tabuleiro para ensinar conhecimentos do currículo no Ensino Fundamental.

Ainda podemos citar Brenelli (1996) quando defendeu que jogos em contextos educacionais seriam eficazes, tanto para garantir o interesse e a motivação como para construir e aprimorar instrumentos cognitivos, favorecendo a aprendizagem. No mesmo caminho, Borin (1998) salientou que a utilização de jogos em aulas de matemática pode diminuir bloqueios e motivar os estudantes frente a disciplina.

Considerando a ideia de que jogos podem ser opções para o ensino de matemática sugerimos um jogo, com a proposta de que os jogadores atribuam significado a noção de Árvores de Possibilidades, que integra o conhecimento referente a combinatória. Para entender melhor do que trata esse conhecimento, podemos utilizar a definição de Borba (2010, p. 01):

A Combinatória é conhecida como a arte de contar, pois nas situações combinatórias são enumeradas maneiras possíveis de combinar dados objetos. Dessa forma, a Combinatória se constitui num ramo da Matemática que estuda técnicas de contagem - direta e implícita - de agrupamentos possíveis, a partir de elementos dados, que satisfaçam a determinadas condições. 


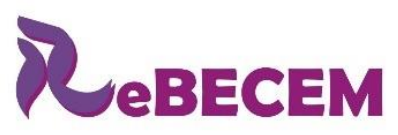

Revista Brasileira de Educação em

Ciências e Educação Matemática

DOI: http://dx.doi.org/10.33238/ReBECEM.2020.v.4.n.1.21884

Para investigar algumas das potencialidades do jogo "Captura da Príncesa", fizemos uma descrição de suas regras e elementos, de como se deu a aplicação para uma turma de estudantes do nono ano do Ensino Fundamental e considerações, obtidas a partir de nossas observações.

\section{Materiais e métodos}

Adotamos como metodologia a pesquisa-ação, que foi definida por Severino (2007, p.120) como aquela em que o pesquisador: “[...] visa intervir na situação, com vistas a modificá-la. [...]”. Assim, propusemos a aplicação do jogo "Captura da Princesa" para abordar problemas de contagem. Propusemos para uma turma do nono ano do Ensino Fundamental uma sessão de jogo em que puderam jogar livremente, testando intuitivamente suas estratégias. Depois disso, intervimos objetivando tratar do princípio fundamental da contagem a partir de árvores de possibilidades e sugerimos uma nova sessão de jogo para verificar se aconteceriam alterações em suas estratégias para vencer as partidas.

Para ajudar em nossa reflexão, decidimos utilizar pressupostos da Teoria das Situações Didáticas, proposta por Brousseau (2002). Essa teoria estuda o processo de ensino e de aprendizagem e propõe um modelo para construção, análise e experimentação de interações entre os alunos e o conhecimento. Assim, essa teoria estuda as interações entre professor, aluno e conhecimento em um movimento dialético. A partir de uma situação de ensino, criada pelo pesquisador e em que sua intencionalidade não fique clara para o aluno, chamada situação adidática, o aluno pode mobilizar dialéticas de ação, formulação e validação. A partir das respostas dos alunos pode ser formulada uma maneira de interagir com a situação adidática. Depois disso o pesquisador institucionaliza o conhecimento que é objetivado pela situação, essa é a dialética de institucionalização.

Durante a aplicação do jogo "Captura da Princesa" os estudantes puderam testar, formular e validar suas estratégias de jogo. Depois disso, o pesquisador institucionalizou uma estratégia de combinatória que permitia conseguir melhores pontuações no jogo. Assim, optamos pelo trabalho em grupos para podermos visualizar as dialéticas de ação, formulação e validação. Depois, assumimos a dialética de institucionalização e observamos se houve mudanças nas estratégias de jogo dos discentes, pois isso poderia ser um indício de aprendizagem. 


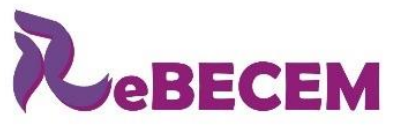

\section{Revista Brasileira de Educação em \\ Ciências e Educação Matemática}

DOI: http://dx.doi.org/10.33238/ReBECEM.2020.v.4.n.1.21884

O jogo que criamos como situação didática foi inspirado no conto de fadas "Pele de Asno". Teixeira (2011) explicou que esse e outros contos de fadas (que são histórias da tradição oral) foram compilados por Charles Perrault na França, no século XVII. Nesse conto, a princesa do reino está em fuga depois da morte de sua mãe, por estar prometida em casamento e devido a sua recusa, decide fugir do reino. No conto de fadas, a princesa conta com a ajuda de um príncipe e se disfarça com a pele de um asno para escapar.

Criamos a necessidade de que os estudantes procurem a princesa, que poderia ser encontrada em diversos locais no reino, representados por cartas:

Figura 1: Cartas que representam os lugares

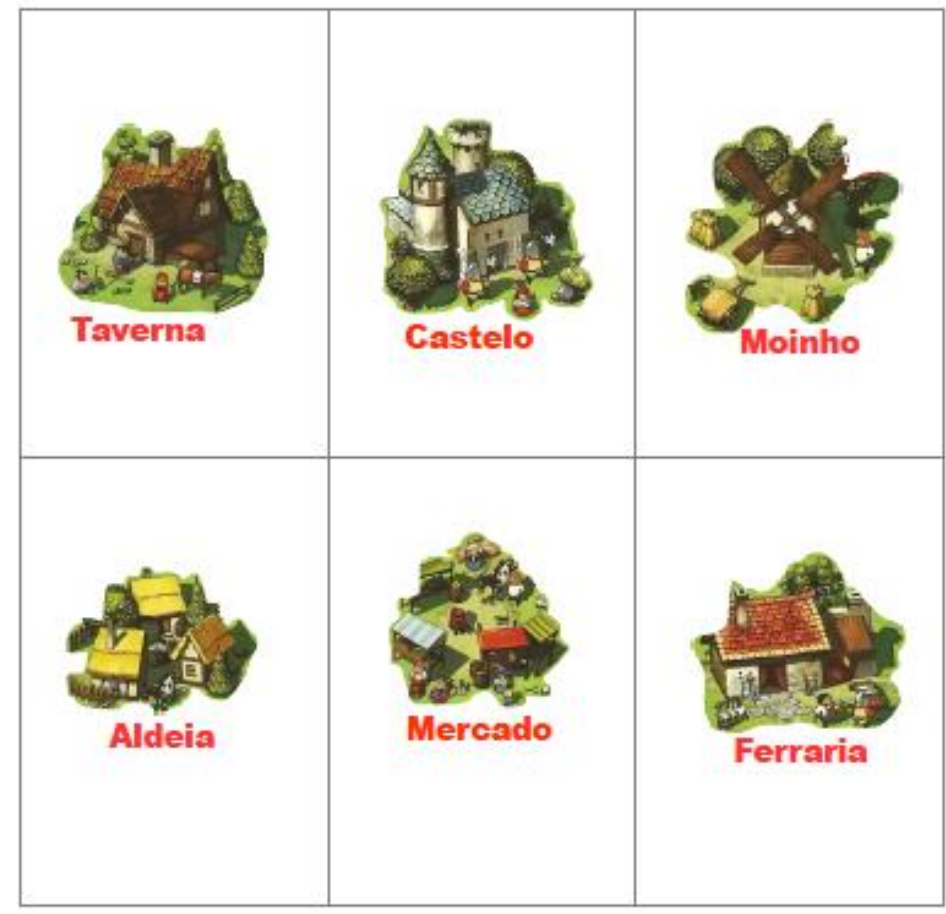

Fonte: Produção do autor

Os jogadores também deveriam descobrir quem foi o cúmplice da fuga, representado pelas cartas a seguir: 


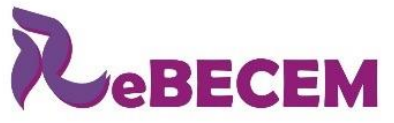

Revista Brasileira de Educação em

Ciências e Educação Matemática

ISSN 2594-9179

DOI: http://dx.doi.org/10.33238/ReBECEM.2020.v.4.n.1.21884

Figura 2: Cúmplices da princesa

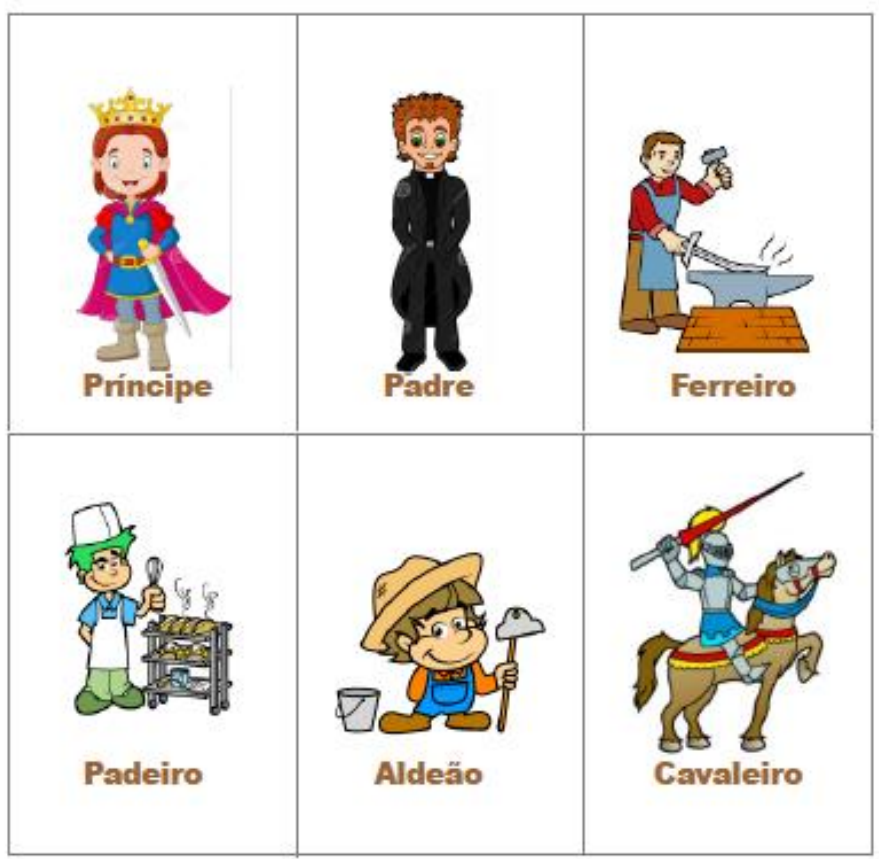

Fonte: Produção do autor

Por último, necessitavam saber qual o disfarce utilizado. Os disfarces possíveis foram os que seguem:

Figura 3: Cartas de disfarce

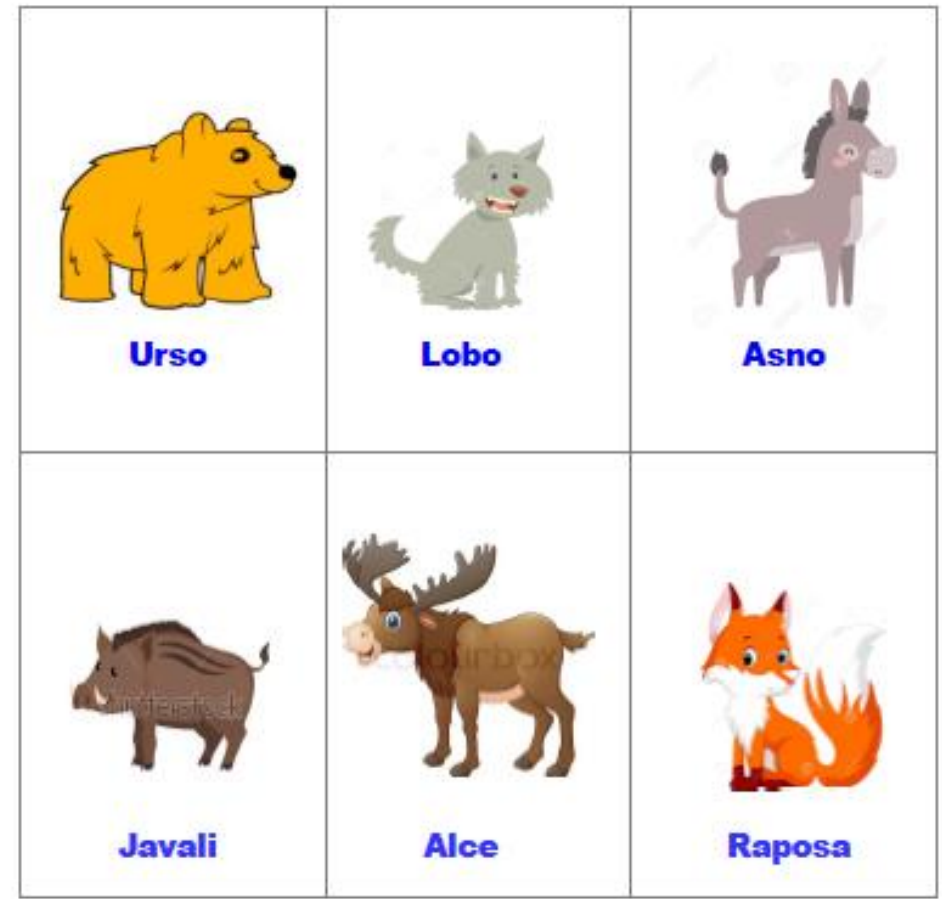

Fonte: Produção do autor 


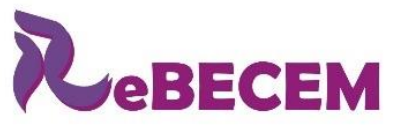

\section{Revista Brasileira de Educação em \\ Ciências e Educação Matemática}

DOI: http://dx.doi.org/10.33238/ReBECEM.2020.v.4.n.1.21884

A organização do jogo foi feita em três pilhas de cartas, uma de locais, outra de possíveis cúmplices e uma terceira com disfarces. Em sua vez, cada estudante poderia virar uma carta para cima e todas eliminariam um local, cúmplice ou disfarce que fosse representado pela carta virada para cima. Por exemplo, no tabuleiro abaixo a primeira carta virada para cima foi a do disfarce de urso e, por isso, sabemos que ele não foi usado pela princesa.

Figura 4: Tabuleiro depois de 1 jogada

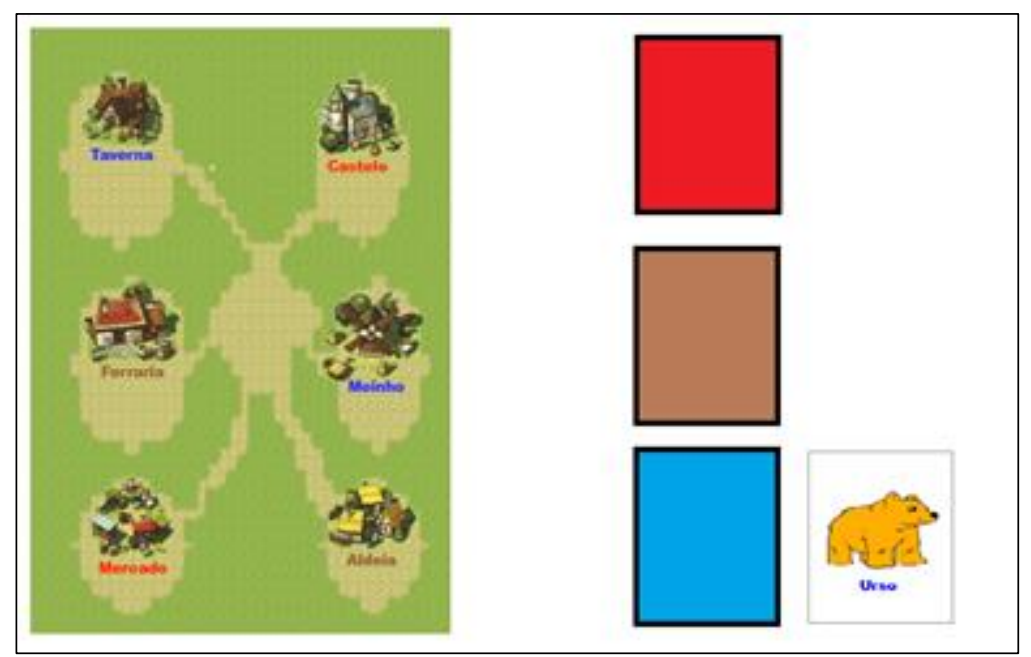

Fonte: Produção do autor

Poderiam ser viradas até cinco cartas em cada pilha, permanecendo ao menos uma carta virada para baixo. Essa última carta é que definiria o lugar onde a princesa se escondeu, com a ajuda de quem e utilizando qual disfarce. Se mais de uma carta fosse deixada virada para baixo, era necessário retirar uma delas aleatoriamente do monte, para definir onde a princesa estava, ajudada por quem e utilizando qual disfarce.

Depois de um número predefinido de jogadas, que variava conforme a quantidade de jogadores na partida, o jogo consistiu em tentar adivinhar onde a princesa se escondeu, com a ajuda de quem e com qual disfarce. Acertos em cada um destes quesitos valeram cinco pontos e venceria o jogo quem chegasse primeiro a trinta.

Um exemplo poderia ser dado com seis estudantes virando uma carta cada em duas rodadas. Dessa forma seriam viradas doze cartas e outras seis ficariam viradas para baixo. Como o máximo de pontos possíveis de serem alcançados em cada rodada era quinze, seriam necessárias no mínimo duas partidas para chegar aos trinta pontos. 


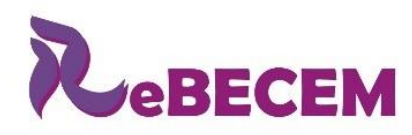

Revista Brasileira de Educação em

Ciências e Educação Matemática

DOI: http://dx.doi.org/10.33238/ReBECEM.2020.v.4.n.1.21884

\section{Aplicação do jogo e institucionalização de uma estratégia}

Esse jogo foi aplicado em uma turma do nono ano do Ensino Fundamental de uma escola pública do município de São Paulo. Depois de formados grupos, com seis estudantes cada, foram explicadas as regras e solicitado aos jogadores que explorassem $o$ jogo. Abaixo, temos o resultado de duas rodadas de cartas viradas para cima

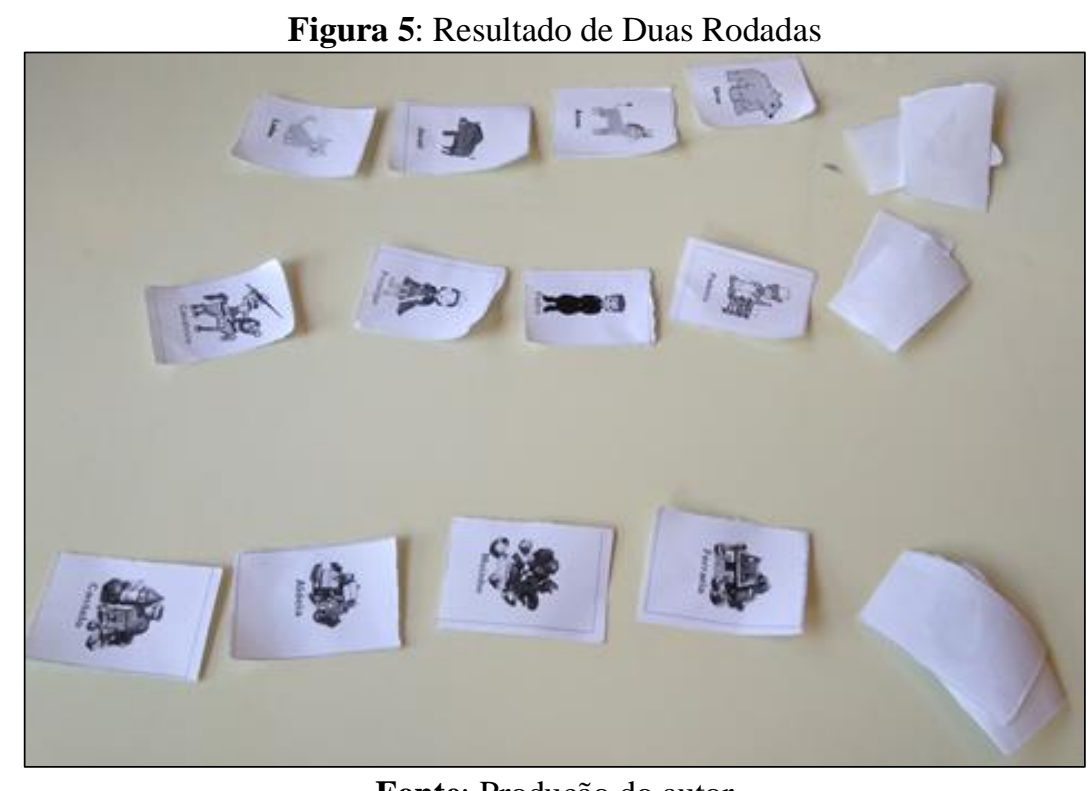

Fonte: Produção do autor

Depois disso, pedimos que tentassem "adivinhar" a resposta correta e o processo foi repetido até que algum dos estudantes chegasse aos trinta pontos.

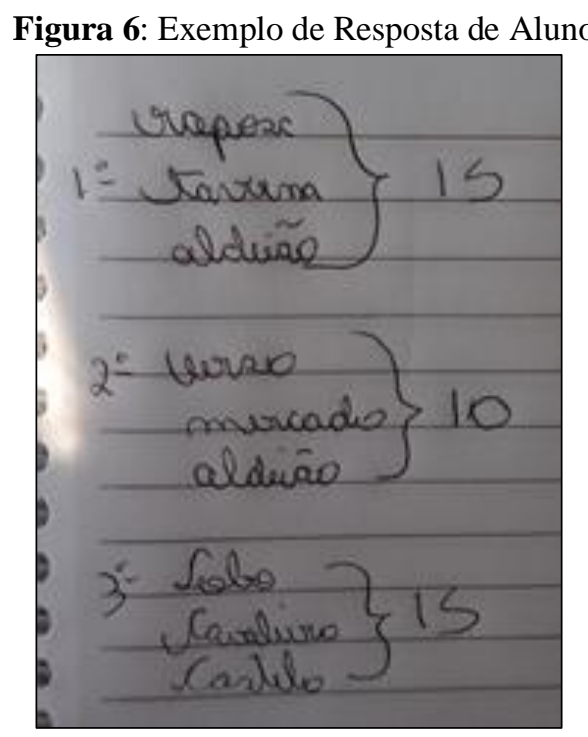

Fonte: Produção do autor 


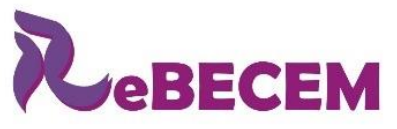

\section{Revista Brasileira de Educação em \\ Ciências e Educação Matemática}

DOI: http://dx.doi.org/10.33238/ReBECEM.2020.v.4.n.1.21884

Terminada a partida, perguntamos quais estratégias foram usadas para pontuar.

Os estudantes responderam que tentaram de maneira aleatória, sem uma estratégia definida. Essa sessão teve a duração de uma aula, ou seja, quarenta e cinco minutos. Em uma segunda sessão, também de quarenta e cinco minutos, as respostas dadas pelos estudantes foram colocadas na lousa e organizadas em árvores de possibilidades, para explicar quantas respostas eram possíveis, em cada partida. Nas Figuras 7 e 8, foram criadas as árvores de possibilidades, representando respostas dos estudantes, presentes na Figura 5.

Figura 7: Árvore de Possibilidades a Partir do Alce

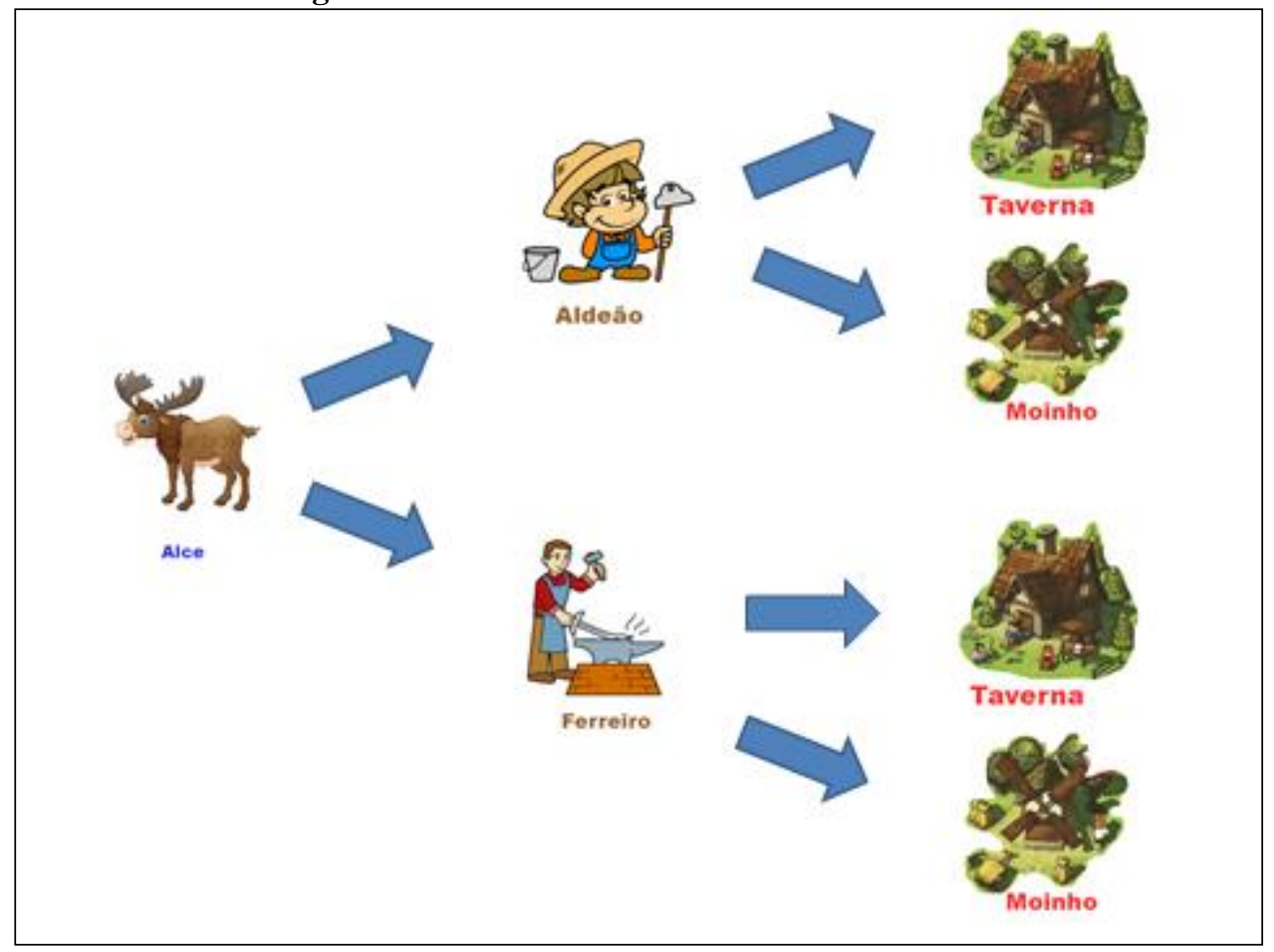

Fonte: Produção do autor

Uma estratégia didática que escolhemos foi disponibilizar 18 cartas aos estudantes, que foram divididos em grupos de 6 pessoas. Escolhemos que fossem feitas 2 rodadas, em que cada um deles viraria uma carta para cima, dessa forma seriam viradas 12 cartas em cada partida, deixando 6 possibilidades de escolha para adivinhar a resposta correta. A ideia era deixar que os estudantes aprendessem as regras e depois lançar a pergunta: Como fazer para aumentar a pontuação em cada rodada? 


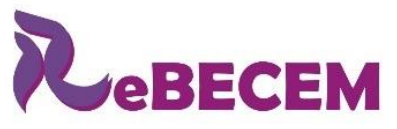

DOI: http://dx.doi.org/10.33238/ReBECEM.2020.v.4.n.1.21884

Figura 8: Árvore de Possibilidades a Partir da Raposa

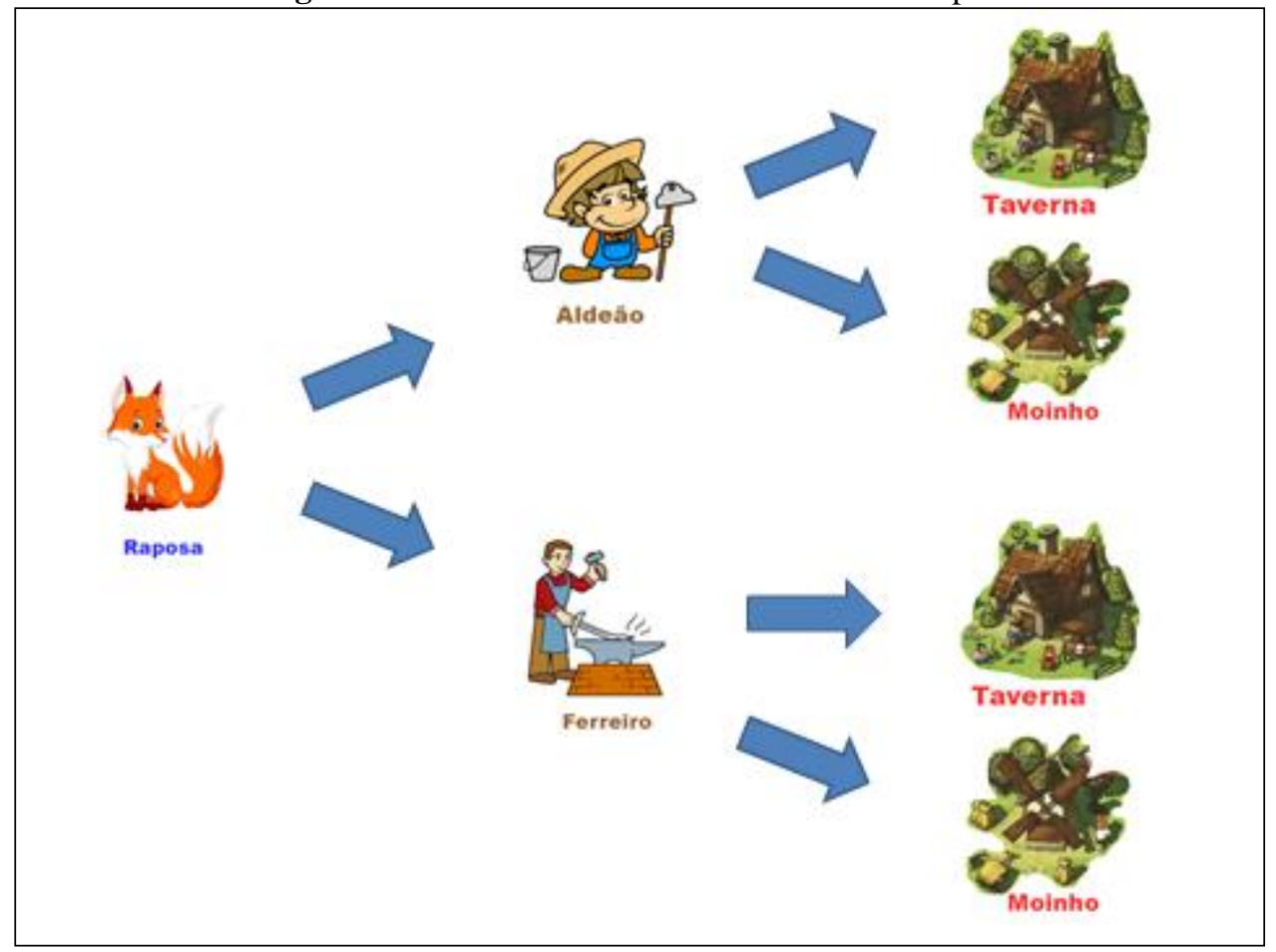

Fonte: Produção do autor

Assim, descobrir como diminuir a quantidade de opções possíveis em cada partida seria uma estratégia ótima para aumentar as chances de vitória no jogo. Por eliminação, os estudantes descobriram que, no caso dessa resposta, a princesa precisaria estar disfarçada de raposa ou de alce. Depois disso precisaram fazer um tipo de aposta, pois a princesa poderia ter sido auxiliada tanto pelo aldeão como pelo ferreiro. Também descobriram que ou ela se escondeu no moinho, ou na taverna.

Por conseguinte, chegaram à conclusão de que nesta partida eram possíveis 8 respostas diferentes, mas só 1 era a certa. Problematizamos com os estudantes como seria possível diminuir a quantidade de possibilidades a um número mínimo, facilitando os "chutes" e a obtenção de pontos.

Os discentes puderam testar hipóteses jogando e chegaram à conclusão de que se o total de cartas eram dezoito, as jogadas eliminavam sempre doze cartas e a árvore tinha três ramos. Explorando essa ideia, concluíram que caso esgotassem ramos da árvore de possibilidades, aumentaria suas chances de pontuar.

Fazendo isso duas vezes, teriam garantidos dez pontos. Continuando esse raciocínio, ficariam com um último ramo com quatro possibilidades. Assim, chegaram à conjectura de que o menor número de possibilidades eram quatro e essa seria a metade das que conseguiram com sua estratégia inicial. Depois disso, exploraram suas 


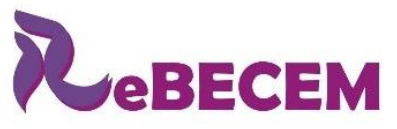

Revista Brasileira de Educação em

Ciências e Educação Matemática

DOI: http://dx.doi.org/10.33238/ReBECEM.2020.v.4.n.1.21884

especulações montando diversas árvores e presumindo diferenças entre a estratégia institucionalizada pelos pesquisadores e as que utilizaram em suas primeiras partidas.

Figura 9: Representação da Conjectura dos Estudantes

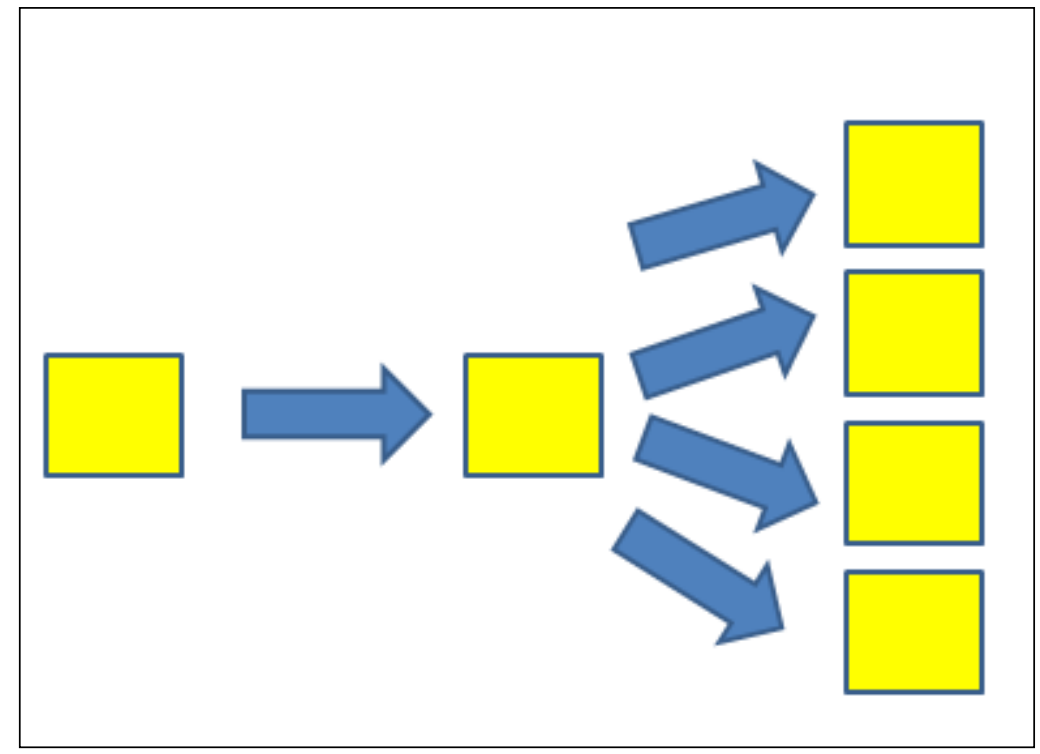

Fonte: Produção do autor

Depois de uma intervenção, problematizamos se aconteceria uma mudança na quantidade de possibilidades invertendo a ordem dos ramos na árvore. Os discentes agiram, formularam e validaram a hipótese de que não seria alterada a quantidade de possíveis respostas. Salientamos que as dialéticas de ação, formulação e validação se deram no contexto da Teoria das Situações Didáticas, como preconizadas por Brousseau (2002). Dessa forma, puderam jogar e testar estratégias baseadas na aleatoriedade.

A seguir, fizemos uma nova sessão de quarenta e cinco minutos e pedimos aos estudantes para jogarem. Nessas novas partidas, observamos que as jogadas foram feitas para diminuir as respostas ao número mínimo de quatro possibilidades, com os estudantes esboçando suas próprias árvores de possibilidades em seus cadernos. Assim, consideramos que a intervenção dos pesquisadores modificou as estratégias de jogo dos estudantes, a partir do conhecimento novo, institucionalizado pelos pesquisadores, referente a árvore de possibilidades.

\section{Considerações}

Analisando o comportamento dos estudantes durante as sessões de jogo, pudemos observar que houver mudanças em suas escolhas. Enquanto na primeira sessão existia aleatoriedade nas jogadas, depois da intervenção foram utilizadas árvores de 
DOI: http://dx.doi.org/10.33238/ReBECEM.2020.v.4.n.1.21884

possibilidades para representar suas novas preferências. Essa alteração foi observada após a intervenção dos pesquisadores, o que nos leva a conjecturar que os estudantes atribuíram significado a esse conhecimento matemático. Por conta disso, consideramos a utilização de jogos, em aulas de matemática, como uma possibilidade que pode ser explorada como alternativa às estratégias tradicionais de ensino.

Consideramos que esse enfoque complementa a ideia de que: "Ensinar não é transferir conhecimento, mas criar as possibilidades para a sua produção ou a sua construção" (FREIRE, 2006, p.22). Para nós, os jogos educativos são uma das alternativas para criar esse tipo de possibilidades no ensino de matemática.

Acreditamos que a proposição de jogos para ensinar matemática pode ser uma estratégia de ensino pertinente, especialmente quando aliada a pressupostos de teorias da Educação Matemática como, por exemplo, a Teoria das Situações Didáticas, que possivelmente potencializam o ensino.

Nosso relato de experiência sobre a aplicação de um jogo de tabuleiro educativo é um exemplo de como os estudantes podem agir, formular e validar suas hipóteses, podendo proporcionar experiências que auxiliem os discentes na tarefa de atribuir sentido aos conhecimentos escolares ao mesmo tempo em que os faz jogar melhor.

A escolha da metodologia da pesquisa ação se mostrou essencial para que fosse feita uma intervenção pelos pesquisadores e esse é um ponto que necessita ser ressaltado. Não consideramos possível que a aplicação de um jogo educativo seja bem-sucedida sem intervenções, mediações e institucionalizações, sob o risco de não haver ensino e, por conseguinte, aprendizagem.

Consideramos que a mudança no jeito de jogar observado, depois da institucionalização de uma nova estratégia, a saber a noção de árvore de possibilidades, foi um indício de que os estudantes atribuíram significado a esse conhecimento matemático. Nossa intenção não é esgotar o assunto e ponderamos acerca da necessidade de o debate especializado discutir este tipo de atividade, em busca de novas estratégias para o ensino. 
Referências

BENELLI, R. P. O jogo como espaço para pensar: A construção de noções lógicas e aritméticas. Campinas/SP. Editora Papirus. 1996.

BORBA, R. E. de S. R. O raciocínio combinatório na educação básica. In: ENCONTRO NACIONAL DE EDUCAÇÃO MATEMÁTICA, 10., 2010. Salvador. Anais... Salavador, 2010.

BORIN, J. Jogos e resolução de problemas: uma estratégia para as aulas de matemática. 3. ed. São Paulo: CAEM-USP, 1998.

BRASIL. Ministério da Educação. Secretaria de Educação Básica. Base nacional comum curricular. Brasília. 2017.

BROUSSEAU, Guy. Theory of didactical situations in mathematics. Traduzido por Nicolas Balacheff, Martin Cooper, Rosamund Sutherland e Virginia Warfield. New York: Kluwer Academic Publishers, 2002.

CARSTENS, A. BECK, J. Get ready for the gamer generation. TechTrends: Linking Research \& Practice to Improve Learning, v. 49, n. 3, p. 22-25, 2005.

FREIRE, P. Pedagogia da autonomia: saberes necessários à prática educativa. São Paulo: Paz e Terra, 2006.

GERONIMO, R. R. Elaboração e proposta de um role playing game (RPG) a partir do papiro de Rhind. 2011. Dissertação (Mestrado em Ensino de Matemática) - Pontifícia Universidade Católica, São Paulo. 2011.

GERONIMO, R. R.; TEIXEIRA, H. G. Criação e aplicação de um jogo educativo: O jogo do observatório. Revista ADVIR (ASDUERJ), v. 2. p. 55-62, 2017.

GERONIMO, R. R. Criação, aplicação e reflexão sobre um jogo educativo: Um relato de prática. Revista Temporis[ação], v. 18. p. 224-236. 2018.

HUIZINGA, J. Homo ludens: O jogo como elemento da cultura. Tradução João Paulo Monteiro. 5. ed. São Paulo: Perspectiva, 2008.

MCGONIGAL, J. A realidade em jogo: Por que os games nos tornam melhores e como eles podem mudar o mundo. Tradução Eduardo Rieche. Editora Best Seller. Rio de Janeiro, 2012.

RIBEIRO, F. D. Jogos e modelagem na educação matemática. São Paulo: Saraiva, 2009.

SEVERINO, A. J. Metodologia do trabalho científico. $23^{\text {a }}$ ed. Cortez: São Paulo, 2007.

TEIXEIRA, L. M. Conto de fadas: pele de asno de Charles Perrault, e sua retomada na modernidade por Marina Colasanti. 2011. Trabalho de Conclusão (Curso de Pedagogia) Universidade Estadual Paulista, Rio Claro. 2011.

Recebido em: 06 de março de 2020

Aceito em: 01 de abril de 2020 